\title{
Effect of dietary transition at dry off on the behavior and physiology of dairy cows
}

\author{
K. M. Dancy, E. S. Ribeiro, and T. J. DeVries* \\ Department of Animal Biosciences, University of Guelph, Guelph, Ontario, N1G 2W1, Canada
}

\section{ABSTRACT}

This study (1) investigated the effect of dietary transition at dry off on the behavior and physiology of Holstein dairy cows and (2) evaluated the efficacy of utilizing reductions in dietary nutrient density and milking frequency to mediate the dry-off process. Forty-eight cows were dried off over a 5-d period approximately $60 \mathrm{~d}$ before their expected calving dates. At the start of dry off (d 1), cows were randomly assigned to 1 of 2 total mixed rations that differed in nutrient density: higher nutrient density (HND; $\mathrm{n}=24$ ) and lower nutrient density (LND; $\mathrm{n}=24$ ). During dry off, cows were milked $1 \times / \mathrm{d}$ on $\mathrm{d} 1,2$, and 3 and a final time on $\mathrm{d} 5$. Milk yield, feeding behavior, rumination, lying behavior, and reticulorumen $\mathrm{pH}$ were monitored electronically and feed samples were collected to determine feed sorting. Blood samples, body condition scores, and body weights were taken periodically. Across treatments, milk yield was reduced by approximately $10 \mathrm{~kg} / \mathrm{d}$ during dry off, with cows fed the LND diet producing 0.9 $\mathrm{kg}$ less milk at the time of dry off compared with cows fed the HND diet. Cows fed the LND diet consumed 2.2 $\mathrm{kg}$ less dry matter per day, fed at a slower rate, spent 15.7 min more feeding, and sorted to a greater extent for the smaller, more nutrient dense components of the diet compared with cows fed the HND diet. Despite sorting activity, cows fed the LND diet ruminated 3.3 min more per kilogram of dry matter consumed and had a mean reticulorumen $\mathrm{pH} 0.07$ units higher compared with cows fed the HND diet. Following the start of dry off, cows spent approximately $5 \%$ more of their free time lying down. Dietary transition and dry off similarly affected the energy balance and inflammatory response of cows, although these parameters varied by day after the start of dry off. The results of this study indicate that the LND diet more effectively reduced milk production before dry off compared with the HND diet while not substantially altering cow physiology.

Received September 19, 2018.

Accepted January 4, 2019.

*Corresponding author: tdevries@uoguelph.ca
Key words: dietary transition, dry off, feeding behavior

\section{INTRODUCTION}

Dairy cows undergo substantial physiological changes during late gestation. Apart from increased nutrient demands for fetal growth, a key event involved in these changes is dry off, wherein the cow transitions from a lactating to a nonlactating state. The nonlactating, or dry, period is widely recognized for its role in promoting successful transition into the subsequent lactation. Additionally, the dry period is important for optimizing milk production in the next lactation, with a dry period length of 40 to $60 \mathrm{~d}$ being commonly practiced (as reviewed by Bachman and Schairer, 2003). Due to high milk production and the target of 12-mo calving intervals, dry off rarely occurs naturally in modern dairy herds. Instead, the dry period is often initiated by abrupt cessation of milking and administration of dry cow therapy (e.g., antibiotic, teat sealer or sealant; Blowey and Edmondson, 2010). The practice of abrupt dry off may have consequences for cow health and welfare, particularly for cows with high production at dry off (e.g., 25-30 kg/d; Dingwell et al., 2001; Stefanon et al., 2002). Researchers have demonstrated that cows with greater production at dry off are at an increased risk of IMI postcalving (Dingwell et al., 2004; Rajala-Schultz et al., 2005) and experience high udder pressure and greater stress levels at dry off (Bertulat et al., 2013).

As an alternative to an abrupt dry off, producers may mediate cessation of milking by gradually reducing milking frequency or by reducing nutrient availability around the time of dry off (Bushe and Oliver, 1987; Skidmore et al., 1997). However, dry-off strategies that restrict feed quantity or quality may also cause cows to experience reduced welfare, at least in the short term. For example, feeding hay of lower digestibility at dry off may cause cows to experience distress due to hunger, as indicated by increased vocalizations (Valizaheh et al., 2008). Increased rates of vocalization have similarly been observed in cows that were restrictively fed 
before dry off (Tucker et al., 2009). Increased plasma NEFA and cortisol have been observed in cows fed only straw at dry off, likely signaling an insufficient supply of nutrients (Odensten et al., 2005, 2007). From these studies, it has been recommended that cows be provided low-quality feed ad libitum rather than be fed restrictively. However, even when fed ad libitum, some forages may not be digestible enough to allow cows to achieve satiety (Valizaheh et al., 2008) and may require supplementation to prevent cows from experiencing negative energy balance (Odensten et al., 2005) and, potentially, depression of immune function (Ster et al., 2012).

As an alternative to feeding solely a low-quality forage at dry off, producers may opt to transition cows to the dry cow diet that they will be fed after dry off. Potential benefits of this strategy are that it limits the number of dietary changes cows must undergo, thereby reducing stress and promoting rumen health, and provides cows with a higher plane of nutrition, which addresses the above-mentioned physiological and welfare concerns. However, the ability of cows to manipulate a mixed ration allows for preferential consumption (sorting) of certain components and thus may result in cows consuming a ration that is nutritionally different than intended (Leonardi and Armentano, 2003; DeVries et al., 2007).

To our knowledge, the behavioral and physiological effect of transition at dry off to diets of lower nutrient densities has not been thoroughly elucidated. Therefore, the objective of this study was to investigate the effect of the magnitude change in dietary nutrient density during and after gradual dry off on behavior and physiology of dairy cows during the first 3 wk following dry off. A secondary objective was to evaluate the efficacy of reducing dietary nutrient density and milking frequency to decrease milk production before dry off.

\section{MATERIALS AND METHODS}

\section{Animals, Housing, and Experimental Design}

This study included 26 primiparous and 22 multiparous Holstein cows (parity $=2.5 \pm 0.7$; mean $\pm \mathrm{SD}$ ) housed at the University of Guelph Livestock Research and Innovation Centre-Dairy Facility (Elora, ON, Canada). Cows were enrolled in late lactation in 8 groups of 6 cows, beginning in June 2016, with the last group being enrolled in December 2016. Groups of 6 comprised cows with similar expected calving dates, and time of enrollment $(\mathrm{d}-16$ relative to the start of dry off) was determined to allow for an average dry period length of $60 \mathrm{~d}$ (actual $=62.6 \pm 8.0 \mathrm{~d}$; mean \pm $\mathrm{SD})$. At the time of enrollment, cows were on average
$297.7 \pm 49.6$ DIM; had an average BW of $741.9 \pm 57.9$ $\mathrm{kg}$ and an average BCS of $3.3 \pm 0.3$; and produced on average $26.0 \pm 5.6 \mathrm{~kg}$ of milk/d during the final $16 \mathrm{~d}$ before the start of dry off. Inclusion criteria required cows be producing at least $10 \mathrm{~kg}$ of milk/d at enrollment. The use of cows and all experimental procedures were in compliance with the guidelines of the Canadian Council on Animal Care (2009) and were approved by the University of Guelph Animal Care Committee (Animal Use Protocol no. 3245).

At least $3 \mathrm{~d}$ before enrollment, each group of 6 cows was moved from the main herd to a separate lactating freestall pen and trained to access individual automated feed bins (Insentec B. V., Marknesse, the Netherlands). This lactating pen had 15 automated feed bins, 30 lying stalls, and 2 water troughs, which offered free access to water. The number of cows in the lactating pen never exceeded 15 cows to ensure that feed bin stocking density remained lower than $100 \%$. The base of the lying stalls was mattresses (Pasture Mat; ProMat, Woodstock, ON, Canada) that were bedded with chopped straw. The $3 \mathrm{~d}$ before enrollment served as an adjustment period during which cows became accustomed to their new social group and to using the feed bins. Cows were then followed for a period of $16 \mathrm{~d}$, during which time baseline data were collected. During the baseline period cows were milked $2 \times / \mathrm{d}$, beginning at 0500 and $1700 \mathrm{~h}$, in a rotary parlor (DeLaval, Peterborough, ON, Canada) and were fed a lactating cow TMR (Table 1) $1 \times /$ d between 1330 and $1430 \mathrm{~h}$. The lactating cow feed bins were cleaned out each day at approximately $1300 \mathrm{~h}$, before the next feed delivery. Lactating cows were fed ad libitum, targeting approximately $10 \%$ refusals (actual $=11.7 \pm 9.5 \%$ on a $\mathrm{DM}$ basis; mean $\pm \mathrm{SD})$.

At the end of the 16-d baseline period, each group of cows was moved to a freestall dry cow pen that contained 12 automated feed bins, 24 lying stalls (mattress base with chopped straw bedding), and 2 water troughs. Similar to when cows were in the lactating pen, the number of cows in the dry pen never exceeded the number of feed bins. In this pen, cows were again assigned to an individual feed bin. Once moved to the dry pen, all cows were dried off over a 5-d period following an intermittent milking schedule. During dry off, all cows were milked only $1 \times / \mathrm{d}$ on $\mathrm{d} 1,2,3$, and 5 at $0500 \mathrm{~h}$ in the parlor and were not milked at all on d 4. Additionally, while a group of cows was being dried off, the dry pen was divided in half by gates to facilitate sorting of cows undergoing dry off from dry cows at milking. After the final milking on d 5, all udder quarters of all cows were treated with a tube of dry cow antibiotic (Dry-Clox, Boehringer Ingelheim Vetmedica Inc., Duluth, GA) followed by a tube of teat 
Table 1. Ingredient and chemical composition (mean $\pm \mathrm{SD}$ ) of the lactating cow and treatment TMR

\begin{tabular}{|c|c|c|c|}
\hline \multirow[b]{2}{*}{ Item } & \multicolumn{3}{|c|}{ Diet } \\
\hline & Lactating & $\begin{array}{l}\text { Higher nutrient } \\
\text { density dry }\end{array}$ & $\begin{array}{c}\text { Lower nutrient } \\
\text { density dry }\end{array}$ \\
\hline \multicolumn{4}{|l|}{ Ingredient, \% DM } \\
\hline Corn silage $^{1}$ & 31 & 44 & 39 \\
\hline Wheat straw ${ }^{2}$ & 4 & 21 & 29 \\
\hline Alfalfa havlage $^{3}$ & 32 & 14 & 12 \\
\hline High-moisture $\operatorname{corn}^{4}$ & 19 & - & - \\
\hline Lactating cow supplement ${ }^{5}$ & 14 & - & - \\
\hline Dry cow supplement ${ }^{6}$ & - & 21 & 19 \\
\hline \multicolumn{4}{|l|}{ Chemical composition $^{7}$} \\
\hline DM, $\%$ & $48.2 \pm 3.0$ & $50.9 \pm 2.8$ & $53.1 \pm 3.1$ \\
\hline $\mathrm{CP}, \%$ of $\mathrm{DM}$ & $14.7 \pm 0.8$ & $12.9 \pm 0.6$ & $12.2 \pm 0.8$ \\
\hline $\mathrm{ADF}, \%$ of $\mathrm{DM}$ & $20.2 \pm 0.5$ & $28.0 \pm 1.2$ & $30.2 \pm 1.1$ \\
\hline $\mathrm{NDF}, \%$ of DM & $29.7 \pm 1.3$ & $41.9 \pm 0.7$ & $46.2 \pm 0.8$ \\
\hline TDN, \% of DM & $72.3 \pm 1.0$ & $67.5 \pm 0.8$ & $64.9 \pm 0.6$ \\
\hline NFC, $\%$ of DM & $48.5 \pm 1.8$ & $38.7 \pm 1.3$ & $34.7 \pm 0.8$ \\
\hline $\mathrm{Ca}, \%$ of DM & $1.0 \pm 0.1$ & $0.8 \pm 0.0$ & $0.8 \pm 0.0$ \\
\hline $\mathrm{P}, \%$ of $\mathrm{DM}$ & $0.4 \pm 0.0$ & $0.4 \pm 0.0$ & $0.3 \pm 0.0$ \\
\hline $\mathrm{NE}_{\mathrm{L}}, \mathrm{Mcal} / \mathrm{kg}$ of $\mathrm{DM}$ & $1.66 \pm 0.02$ & $1.55 \pm 0.02$ & $1.48 \pm 0.02$ \\
\hline
\end{tabular}

${ }^{1}$ Corn silage had a DM of $39.5 \pm 2.0 \%$ and a chemical composition (DM basis) of $7.0 \pm 0.7 \%$ CP, $19.4 \pm 0.5 \%$ $\mathrm{ADF}, 32.6 \pm 0.5 \% \mathrm{NDF}$, and $54.0 \pm 1.1 \% \mathrm{NFC}$.

${ }^{2}$ Straw had a DM of $90.8 \pm 2.8 \%$ and a chemical composition (DM basis) of $4.4 \pm 2.2 \% \mathrm{CP}, 52.3 \pm 0.5 \%$ ADF, and $76.3 \pm 3.5 \% \mathrm{NDF}$.

${ }^{3}$ Alfalfa haylage had a DM of $38.0 \pm 6.2 \%$ and a chemical composition (DM basis) of $19.2 \pm 3.3 \% \mathrm{CP}, 32.6 \pm$ $1.1 \% \mathrm{ADF}$, and $39.0 \pm 0.6 \% \mathrm{NDF}$.

${ }^{4}$ High-moisture corn had a DM of $74.0 \pm 2.6 \%$ and a chemical composition (DM basis) of $8.0 \pm 1.3 \% \mathrm{CP}, 2.8$ $\pm 0.4 \% \mathrm{ADF}$, and $8.5 \pm 0.8 \% \mathrm{NDF}$.

${ }^{5}$ Supplied by Floradale Feed Mill Ltd. (Floradale, ON, Canada). Ingredients (as fed): $38.2 \%$ soybean meal, $24.1 \%$ Soy Plus, $12.3 \%$ canola, $4.1 \%$ fish meal (herring), $3.9 \%$ limestone calcium carbonate, $3.5 \%$ sodium sesquicarbonate, $3.2 \%$ fine salt, $2.4 \%$ monocalcium phosphate, $1.7 \%$ magnesium oxide, $1.6 \%$ Diamond V Yeast XP, $1.4 \%$ biuret, $0.8 \%$ DCAD+ (potassium carbonate), $0.8 \%$ urea, $0.8 \%$ FFM Org Ruminant Micro P, $0.6 \%$ tallow, $0.4 \%$ sulfur $99.5 \%, 0.1 \%$ Metasmart, $0.04 \%$ Rumensin, and $0.02 \%$ Selplex 2000 . Lactating cow supplement had a DM of $92.0 \pm 0.9 \%$ and a chemical composition (DM basis) of $43.7 \pm 1.3 \% \mathrm{CP}, 9.0 \pm 0.2 \% \mathrm{ADF}$, and $14.4 \pm 0.5 \% \mathrm{NDF}$.

${ }^{6}$ Supplied by Floradale Feed Mill Ltd. Ingredients (as fed): $24.1 \%$ Soy Plus, $18.0 \%$ soy hulls (ground), $17 \%$ canola, $13.6 \%$ wheat shorts, $8.5 \%$ soybean meal, $2 \%$ Diamond V Yeast XP, $1.9 \%$ limestone calcium carbonate, $1.3 \%$ magnesium oxide, $1.0 \%$ vitamin E, $1.0 \%$ fine salt, $1.0 \%$ tallow, 0.5\% FFM Org Ruminant Micro PRX, $0.07 \%$ Selplex 2000, 0.05\% Rumensin, and 0.01\% Rovimix Biotin 20,000. Dry cow supplement had a DM of $91.7 \pm 1.4 \%$ and a chemical composition (DM basis) of $31.1 \pm 0.1 \% \mathrm{CP}, 18.4 \pm 1.1 \% \mathrm{ADF}$, and $31.2 \pm 1.1 \%$ NDF.

${ }^{7}$ Values were obtained from chemical analysis of TMR samples. $\mathrm{NE}_{\mathrm{L}}$ was calculated based on NRC (2001) equations.

sealant (Orbeseal, Pfizer Inc., Kirkland, QC, Canada). Before infusion, all teats were disinfected with alcohol.

At the start of gradual dry off (d 1), cows within each group were randomly assigned to 1 of 2 dry cow treatment diets (Tables 1 and 2), balanced for parity and milk production between treatments. The treatments were higher nutrient density $(\mathbf{H N D} ; \mathrm{n}=24$ ) or lower nutrient density (LND; n = 24) dry cow diets. The treatment diets contained the same feed ingredients but differed in the proportion of each feed ingredient. From the start of dry off $(\mathrm{d} 1)$, cows were fed $1 \times / \mathrm{d}$ between 1030 and $1130 \mathrm{~h}$. The dry cow feed bins were cleaned out each day at approximately $1000 \mathrm{~h}$, before the next daily feed delivery. After dry off (d 5), cows continued to receive their treatment diet for an additional $21 \mathrm{~d}$, for a total of $26 \mathrm{~d}$ on their assigned treatment diet.
Both treatment diets were fed ad libitum, again targeting approximately $10 \%$ refusals (actual $=11.8 \pm 9.3 \%$ on a $\mathrm{DM}$ basis; mean $\pm \mathrm{SD}$ ). Access to water was also ad libitum while cows were in the dry cow pen, with no water restriction occurring during dry off. After d 26, cows were fed the HND diet until calving, which was the standard dry cow ration for the herd.

\section{Milk Yield and Components}

From enrollment $(\mathrm{d}-16)$ until the end of dry off (d 5), milk yield was recorded automatically at every milking by DelPro software (DeLaval, Peterborough, ON, Canada). Milk samples were collected from each cow at both milkings on $\mathrm{d}-11,-10,-4,-3,3$, and 5 . These samples were sent to the DHI testing laboratory 
(CanWest DHI, Guelph, ON, Canada) for component analysis (fat, protein, MUN, and SCC) using a Fourier transform infrared full spectrum analyzer (Milkoscan FT+ and Milkoscan 6000; Foss, Hillerød, Denmark). One value per cow on each sampling day was obtained by calculating the average across milkings.

\section{Feed Sampling and Analysis}

Throughout the duration of the study, 2 duplicate samples of each of the 3 diets (lactating and 2 dry cow treatment diets) were collected $3 \mathrm{~d} / \mathrm{wk}$ at feed delivery time. One of the duplicate samples was used to determine DM content and chemical composition, whereas the other was used to determine particle size distribution. At the beginning of each month, samples of each of the TMR components (for all diets) were taken for DM and composition analysis. In addition to samples taken of offered (fresh) feed, refusal (orts) samples were collected regularly for particle size determination from the automated feed bins of enrolled cows, with a total of 17 refusal samples for each cow. Sampling frequency of refusals was approximately every $3 \mathrm{~d}$ but was more frequent around the time of dry off and dietary transition $(\mathrm{d}-14,-11,-8,-5,-2,-1,1,3,5,6,7,10,13$, 16, 19, 22, and 25). Upon collection, all samples were frozen at $-20^{\circ} \mathrm{C}$ until further analysis. Before analysis, all samples were given a period of at least $24 \mathrm{~h}$ to thaw in a refrigerator.

Each fresh feed sample taken for nutrient determination was oven-dried at $55^{\circ} \mathrm{C}$ for $48 \mathrm{~h}$ to determine DM.
To assess sorting behavior, the other fresh feed sample and all orts samples were separated by particle size using a 4-screen Penn State Particle Separator (PSPS; Maulfair et al., 2011; Maulfair and Heinrichs, 2013). The PSPS separated samples into 4 particle size fractions: long (>19 mm), medium $(8-19 \mathrm{~mm})$, short $(4-8$ $\mathrm{mm})$, and fine $(<4 \mathrm{~mm})$. After being separated into fractions, PSPS samples were also oven-dried at $55^{\circ} \mathrm{C}$ for $48 \mathrm{~h}$.

Sorting behavior of each particle size was quantified by comparing the particle size distribution of the offered feed with that of the refused feed of individual cows. Specifically, sorting of each PSPS fraction was calculated as the actual intake of a fraction divided by the predicted intake of the fraction, expressed as a percentage (Leonardi and Armentano, 2003). For each fraction, the actual intake was calculated as the amount refused of the fraction subtracted from the amount offered (on a DM basis), whereas the predicted intake was calculated as the cow's DMI of the complete ration multiplied by the percentage of the fraction in the offered ration (on a DM basis). A sorting value of $100 \%$ indicated that no sorting of the fraction occurred: actual intake equaled predicted intake. A sorting value $<100 \%$ indicated that sorting occurred against the fraction: actual intake was less than predicted intake. Finally, a sorting value $>100 \%$ indicated that sorting occurred in favor of the fraction: actual intake was greater than predicted intake. The difference of the sorting value from $100 \%$ indicated the degree to which sorting occurred.

Table 2. Particle size distribution ${ }^{1}$ (mean $\pm \mathrm{SD}$ ) and nutrient content (mean $\pm \mathrm{SD}$ ) by particle size of the fresh experimental diets

\begin{tabular}{|c|c|c|c|}
\hline \multirow[b]{2}{*}{ Item } & \multicolumn{3}{|c|}{ Diet } \\
\hline & Lactating & $\begin{array}{l}\text { Higher nutrient } \\
\text { density dry }\end{array}$ & $\begin{array}{l}\text { Lower nutrient } \\
\text { density dry }\end{array}$ \\
\hline \multicolumn{4}{|c|}{ DM, \% retained on screen } \\
\hline Long & $6.1 \pm 2.4$ & $11.1 \pm 3.9$ & $14.7 \pm 5.5$ \\
\hline Medium & $44.0 \pm 4.2$ & $41.0 \pm 4.4$ & $38.1 \pm 3.7$ \\
\hline Short & $16.3 \pm 1.6$ & $14.9 \pm 1.5$ & $15.3 \pm 1.5$ \\
\hline Fine & $33.6 \pm 4.1$ & $33.0 \pm 5.0$ & $31.9 \pm 4.7$ \\
\hline \multicolumn{4}{|c|}{$\mathrm{ADF}^{2} \%$ of screen DM } \\
\hline Long & - & $35.8 \pm 0.9$ & $38.1 \pm 0.9$ \\
\hline Medium & - & $29.9 \pm 0.2$ & $31.8 \pm 0.2$ \\
\hline Short & - & $23.6 \pm 1.6$ & $26.3 \pm 0.1$ \\
\hline Fine & - & $22.0 \pm 0.7$ & $24.6 \pm 0.5$ \\
\hline \multicolumn{4}{|c|}{$\mathrm{NDF}^{2}, \%$ of screen DM } \\
\hline Long & - & $53.4 \pm 1.5$ & $56.6 \pm 0.6$ \\
\hline Medium & - & $45.2 \pm 0.6$ & $49.2 \pm 0.9$ \\
\hline Short & - & $36.5 \pm 0.1$ & $40.4 \pm 1.6$ \\
\hline Fine & - & $33.5 \pm 0.9$ & $36.3 \pm 0.6$ \\
\hline
\end{tabular}

${ }^{1}$ Particle size determined by processing feed samples with the Penn State Particle Separator (Maulfair et al., 2011; Maulfair and Heinrichs, 2013), which has a 19-mm screen (long), an 8-mm screen (medium), a 4-mm screen (short), and a pan (fine).

${ }^{2}$ Values were obtained from chemical analysis of TMR samples separated by particle size with the Penn State Particle Separator. 
After being dried, all DM samples (feed components and fresh TMR samples) as well as fresh PSPS fraction samples of the 3 diets were ground through a 1-mm sieve (model 4 Wiley laboratory mill, Thomas Scientific, Swedesboro, NJ). Ground samples were then pooled by sample type and date and shipped to Cumberland Valley Analytical Services Inc. (Waynesboro, $\mathrm{PA})$ for analysis of $\mathrm{DM}\left(135^{\circ} \mathrm{C}\right.$; AOAC International, 2000: method 930.15$)$, ash $\left(535^{\circ} \mathrm{C}\right.$; AOAC International, 2000: method 942.05), ADF (AOAC International, 2000: method 973.18), NDF with heat-stable $\alpha$-amylase and sodium sulfite (Van Soest et al., 1991), and CP $(\mathrm{N} \times 6.25 ;$ AOAC International, 2000: method 990.03; Leco FP-528 Nitrogen Analyzer, Leco, St. Joseph, MI).

\section{Feeding Behavior}

Automated feed bins were used to individually measure each cow's feeding behavior and DMI, as validated by Chapinal et al. (2007). At each visit to the bin, duration of the visit (feeding time) and feed consumed (start weight - end weight; as-fed intake) were recorded. To determine DMI, the as-fed intake at each bin visit was multiplied by the weekly average DM percentage of the corresponding diet, as determined by DM analysis of fresh feed samples. Feeding rate at each bin visit was calculated as DMI $(\mathrm{kg} / \mathrm{d})$ divided by time spent feeding $(\mathrm{min} / \mathrm{d})$. These data were then summarized to determine total DMI $(\mathrm{kg} / \mathrm{d})$ and feeding time $(\mathrm{min} / \mathrm{d})$ as well as the average feeding rate $(\mathrm{kg} / \mathrm{min})$ for each trial day for each cow. To analyze meal patterning, individual bin visits were combined into meals using individual meal criteria for each cow, as described by DeVries et al. (2003). Separate meal criteria (the minimum time between meals) were determined for each cow for both the lactating and dry periods using a software package (MIX 3.1.3; MacDonald and Green, 1988) to fit normal distributions to the frequency of $\log _{10}$-transformed time intervals between bin visits. If an interval of time between 2 bin visits exceeded the determined meal criteria, then this indicated a different meal. The number of different meals was classified as meal frequency (no./d). Total meal time was the time between the start of the first bin visit until the end of the last bin visit within the meal criterion. Meal length $(\mathrm{min} / \mathrm{meal})$ was calculated as the total meal time divided by the meal frequency. Finally, meal size $(\mathrm{kg} / \mathrm{d})$ was calculated as DMI divided by the meal frequency.

\section{Rumination}

As validated by Schirmann et al. (2009), an electronic monitoring system (HR-TAG-LD, SCR Engineers Ltd., Netanya, Israel) was used to monitor rumination activ- ity. A rumination data logger attached to a nylon collar was fitted to each cow before enrollment and was used to measure rumination activity $24 \mathrm{~h} / \mathrm{d}$ for the 6 -wk period. Rumination data were automatically uploaded to a receiver at 2-h intervals and downloaded at least $1 \times /$ wk. Data were then summarized by cow and trial day.

\section{Lying Behavior}

Lying and standing behavior were recorded with electronic data loggers (HOBO Pendant G Data Logger, Onset Computer Corp., Bourne, MA), which took measurements of leg orientation at 1-min intervals, as validated by Ledgerwood et al. (2010). Data loggers were wrapped in veterinary bandage (VetRap; 3M Products, St. Paul, MN) and attached to the medial side of the lower hind leg, also using veterinary bandage. Cows were fitted with their first data logger before enrollment. Data loggers were removed $1 \times /$ wk to download data and to prevent prolonged exposure to rubbing on a particular leg. Before removing one data logger, a new data logger was fitted to the other hind leg of the cow in order to keep data continuous. Data collected were downloaded using Onset HOBOware Software (Onset Computer Corp.) and exported to Microsoft Excel (Microsoft, Redmond, WA). Excel macros were used to process and summarize lying data as total lying time, frequency of lying bouts, and average bout length (total lying time/frequency of bouts).

\section{Reticulorumen $\mathrm{pH}$}

To measure rumen health, each cow was administered a wireless telemetric bolus (eBolus, eCow Ltd., Devon, UK), as validated by Falk et al. (2016), before enrollment using a balling gun. Each bolus took measurements of reticulorumen $\mathrm{pH}$ at 15-min intervals 24 $\mathrm{h} / \mathrm{d}$. Data were downloaded from the boluses at least $1 \times /$ wk using a handset and antenna. Downloaded files were combined into a continuous record for each cow, and data were summarized as mean, maximum, and minimum $\mathrm{pH}$ as well as range in $\mathrm{pH}$ by day and cow.

\section{Blood Sampling and Analyses}

A total of 8 blood samples were taken from the coccygeal vein of each cow into 10 -mL red top evacuated tubes on $\mathrm{d}-14,-7,1,5,7,13,19$, and 25. All blood samples were taken at the same time each day (between 1000 and $1100 \mathrm{~h}$ while cows were in the dry pen and 1200 and $1300 \mathrm{~h}$ while cows were in the lactating pen). Blood samples were left to sit at room temperature for a period of $1 \mathrm{~h}$ following collection to allow coagulation and to facilitate fibrinogen breakdown. After $1 \mathrm{~h}$, sam- 
ples were centrifuged at $1,500 \times g$ at $18^{\circ} \mathrm{C}$ for $15 \mathrm{~min}$ to separate cells from serum. For each blood sample, 1.5 $\mathrm{mL}$ of serum was placed into 3 - $\mathrm{mL}$ tubes to be frozen at $-20^{\circ} \mathrm{C}$ until the time of analysis. Serum samples were sent to the Animal Health Laboratory, University of Guelph, where they were analyzed for nonesterified fatty acids (NEFA), glucose, and haptoglobin concentrations using a photometric test. Additionally, an electronic hand-held meter (FreeStyle Precision Neo, Abbott Diabetes Care, Saint Laurent, QC, Canada), as validated by Kanz et al. (2015), was used to measure BHB concentration (mmol/L) immediately following blood collection by placing 1 drop of blood on a blood ketone test strip.

\section{$B W$ and BCS}

Body weight and BCS were recorded periodically for each group of cows. Body weight was measured by bringing cows to a scale (1-20W scale, Ohaus, Dundas, ON, Canada) at enrollment (d -16 and -15$)$, during dry off (d 3 and 5 ), and at the end of each study period (d 25 and 26). Cows were weighed twice at each time point so an average could be calculated to better account for daily variation. During dry off, BW was not measured on consecutive days to avoid bringing cows to the scale on days when they were not being milked because the scale was near the milking parlor. Body condition score was conducted on a 5-point scale as described by Wildman et al. (1982) at 0.25 increments at enrollment $(\mathrm{d}-16)$, at dry off $(\mathrm{d} 5)$, and at the end of the study period (d 26). All BCS assessments were performed by a single assessor.

\section{Statistical Analyses}

All statistical analyses were conducted using SAS 9.4 software (SAS Institute Inc., 2013). Significance was declared if $P \leq 0.05$ and tendencies were reported if $0.05<P \leq 0.10$. Before analyses, the UNIVARIATE procedure was used to assess the normality of all measures. The assumptions of normality were met for most variables; however, the natural logarithm was used to normalize SCC, NEFA, and haptoglobin data sets. Dietary treatment was applied at the level of the cow; thus, cow was the experimental unit. Due to the technical failure of 2 rumination data loggers, all rumination activity analyses were conducted using a sample size of 46 cows (HND, $\mathrm{n}=23$; LND, $\mathrm{n}=23$ ). The data for 1 cow were removed from all analyses involving feeding behavior, lying behavior, and blood parameters because the cow's data were consistently an outlier due to chronic lameness and illness (HND, $\mathrm{n}=24$; LND, $\mathrm{n}$
$=23)$. In instances where malfunctioning of automated feed bins, data loggers, or telemetric boluses resulted in the loss of data for partial or entire days, only days with complete data were included in the analyses.

To investigate the effect of dry off and dietary treatment on milk yield and composition, DMI, feeding behavior, feed sorting, rumination, lying behavior, reticulorumen $\mathrm{pH}$, energy balance, and haptoglobin, data were summarized by day and cow and analyzed in mixed-effect linear regression models using the MIXED procedure of SAS, treating day after the start of dry off as a repeated measure. In each model, treatment, day, and treatment $x$ day interaction were included as fixed effects. To account for pre-existing variability, the average values of each measure during the baseline period were included as covariates in all models. As allocation to treatments was balanced for milk production and parity, these variables were tested in the models but not included, as they did not change the estimates or significance for fixed effects. The random effect was group, referring to the 8 groups of 6 cows included in the study. The subject of the repeated measures statement was cow within group. For each model, several covariance structures were considered, and that with the best fit based on Schwarz's Bayesian information criterion was used for each model. Covariance structures used were compound symmetry, heterogeneous compound symmetry, autoregressive (1), and heterogeneous autoregressive (1). Treatment $\times$ day interactions were considered at $P<0.05$ and investigated using the PDIFF procedure in the LSMEANS statement. Additionally, a difference from the baseline period was assessed for each variable for each treatment. This was performed on a within-cow basis by subtracting the baseline average of each measure from the value of that measure for each day during the treatment period. These models were created identically to those described above except the dependent variable in each case was the difference in that variable from their baseline average (and the baseline average was not included as a covariate). Finally, to determine whether sorting occurred within treatments and during the baseline period, the summarized sorting values for each particle size were tested for a difference from 100 using $t$-tests.

To determine whether there was an effect of dietary treatment on BW and BCS, models were created using the MIXED procedure wherein BW and BCS at the end of the study were the dependent variables, treatment was the fixed effect, and BW or BCS at enrollment were included as a covariate. Group was also included as a random effect. The change in BW and BCS was calculated as the difference between enrollment and end values and was modeled similarly, with treatment as a fixed effect. 


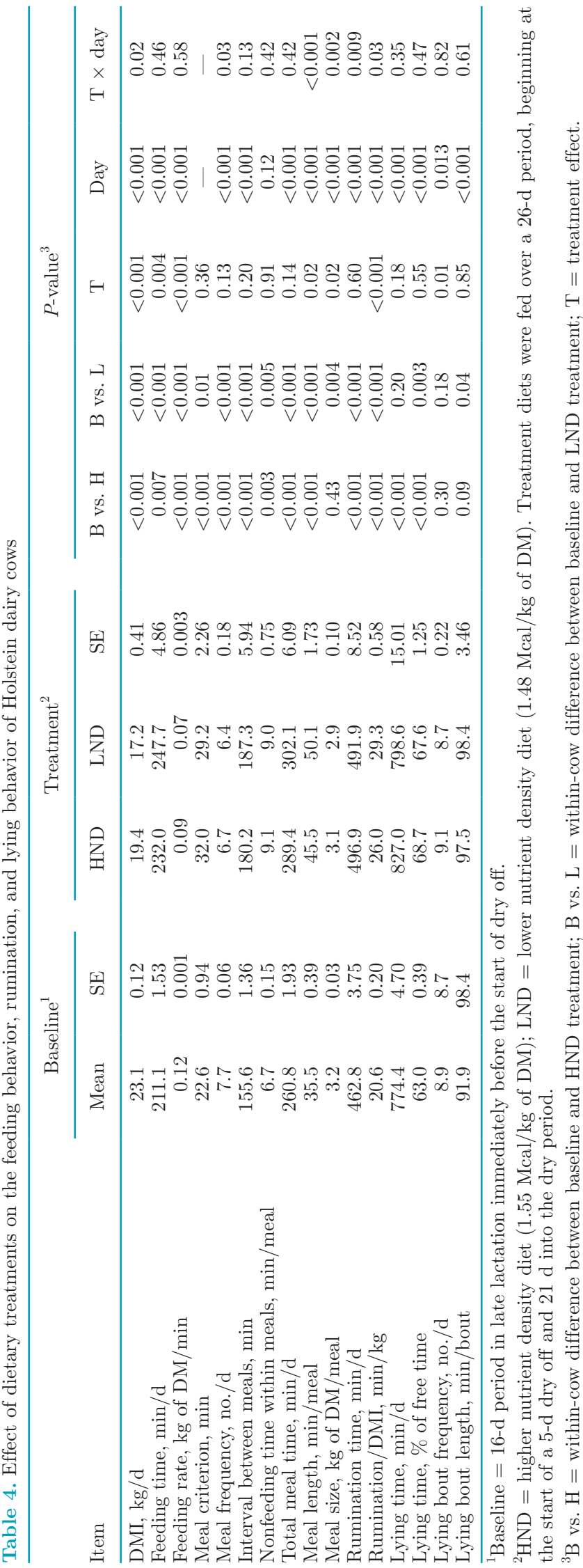

sorted in favor of the fine particles $(<4 \mathrm{~mm})$ during the baseline period and continued to do so similarly when fed the HND diet in the treatment period (Table $5)$. However, cows fed the LND diet sorted in favor of the fine particles to a greater extent than during the baseline period. A treatment $\times$ day interaction was detected for the treatment period (Table 5), wherein sorting of the fine particles was greater for LND cows than HND cows $(P<0.06)$ with the exception of $\mathrm{d} 13$ and $25(P>0.20)$.

Compared with the baseline period, both rumination time and rumination time per kilogram of DMI (rum/ DMI) were greater in the treatment period (Table 4). A treatment $x$ day interaction indicated that rumination time was similar between treatments (Table 4) with the exception of $\mathrm{d} 6,7$, and 14, wherein LND cows spent more time ruminating than HND cows $(P$ $<0.05$ ), and d 4, wherein LND cows tended to spend more time ruminating than HND cows $(P<0.07)$. A treatment $\times$ day interaction was also detected for rum/ DMI (Table 4), in which case rum/DMI was greater for LND cows than HND cows except for d 5, 9, 13, 14, 20, 22, and 25, where rum/DMI was similar between treatments.

Compared with the baseline period, cows had higher daily mean and daily minimum reticulorumen $\mathrm{pH}$ in the treatment period (Table 6). Daily maximum $\mathrm{pH}$ was higher than baseline for LND cows but was similar to baseline for HND cows. Mean, maximum, and minimum reticulorumen $\mathrm{pH}$ differed by treatment, with cows fed the LND diet having higher $\mathrm{pH}$ in each regard compared with those fed the HND diet. During the treatment period, cows had smaller within-day range in $\mathrm{pH}$ compared with that observed during the baseline period. Daily range in reticulorumen $\mathrm{pH}$ also differed between treatments, with LND cows having a slightly lower daily range in $\mathrm{pH}$ compared with HND cows.

Although daily lying time was higher than baseline for HND cows, lying time did not differ between LND cows and HND cows during the treatment period (Table 4). When calculated as a percentage of free time (time not including time spent feeding), there was similarly no difference in lying time between LND and HND cows. Lying bout frequency was similar to that during the baseline period for both treatments; however, cows fed the LND diet had fewer bouts per day than cows fed the HND diet. Finally, cows fed the LND diet had longer bouts compared with their baseline and cows fed the HND diet tended to have longer bouts compared with their baseline. However, no difference in average bout length was observed between treatments.

Although no treatment differences were detected for glucose, NEFA, or haptoglobin, these parameters varied by day relative to treatment implementation and 

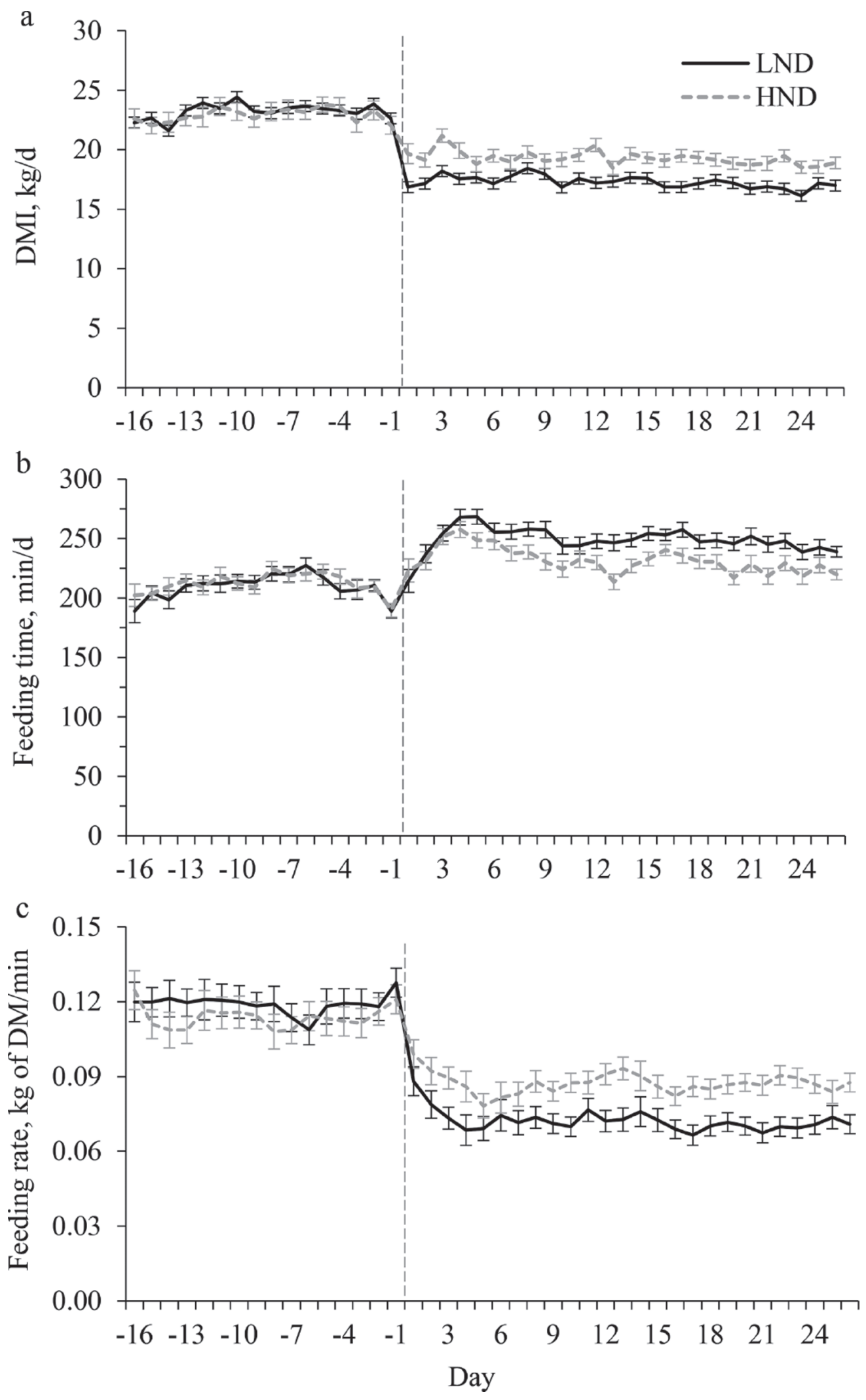

Figure 1. Daily $( \pm \mathrm{SE})(\mathrm{a}) \mathrm{DMI}(\mathrm{kg} / \mathrm{d})$, (b) feeding time (min/d), and (c) feeding rate $(\mathrm{kg}$ of DM/min) for cows fed 1 of 2 dietary treatments differing in ration nutrient density (LND = lower nutrient density; HND = higher nutrient density) undergoing a 5 -d dry off beginning at $\mathrm{d} 1$ (dotted vertical line). 
Table 5. Effect of dietary treatments on the sorting $(\%)^{1}$ behavior of groups of Holstein dairy cows

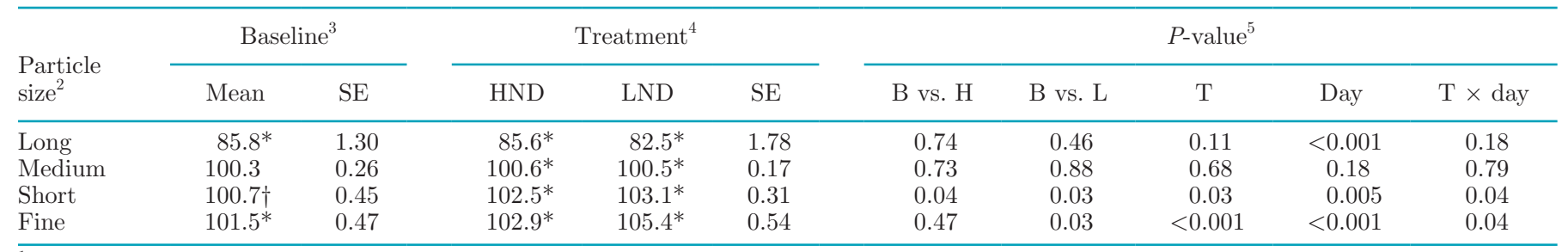

${ }^{1}$ Sorting percentage $=($ actual DMI of a particle size/predicted DMI of a particle size $) \times 100$. Sorting values of $100 \%$ indicate no sorting, $<100 \%$ indicate sorting against the particle size, and $>100 \%$ indicate sorting in favor of the particle size.

${ }^{2}$ Particle size determined by a Penn State Particle Separator (Maulfair et al., 2011; Maulfair and Heinrichs, 2013), which has a 19-mm screen (long), an 8-mm screen (medium), a 4-mm screen (short), and a pan (fine).

${ }^{3}$ Baseline $=16$-d period before the start of dry off.

${ }^{4} \mathrm{HND}=$ higher nutrient density $\operatorname{diet}(1.55 \mathrm{Mcal} / \mathrm{kg}$ of $\mathrm{DM} ; \mathrm{n}=24) ; \mathrm{LND}=$ lower nutrient density $\operatorname{diet}(1.48 \mathrm{Mcal} / \mathrm{kg}$ of $\mathrm{DM}$; $\mathrm{n}=23)$. Treatment diets were fed over a 26-d period, beginning at the start of a 5-d dry off and $21 \mathrm{~d}$ into the dry period.

${ }^{5} \mathrm{~B}$ vs. $\mathrm{H}=$ within-cow difference between baseline and HND treatment; $\mathrm{B}$ vs. $\mathrm{L}=$ within-cow difference between baseline and LND treatment; $\mathrm{T}=$ treatment effect.

*Difference in sorting values from $100 \% P<0.05$. $\dagger$ Difference in sorting values from $100 \% P<0.10$.

dry off as well as from baseline (Table 7). Cows fed the HND diet had increased glucose from d 5 to $19(P$ $<0.05)$, whereas cows fed the LND diet had increased glucose on $\mathrm{d} 5$ and $7(P<0.04)$ and showed a tendency for elevated glucose on d 13 and $19(P<0.08$; Figure 2a). Cows fed the HND diet had lower NEFA on $d 7$ and 25 compared with baseline $(P<0.02)$, whereas cows fed the LND diet tended to have higher NEFA on d 1 and lower NEFA on d $25(P<0.08)$ and had lower NEFA on d $7(P=0.002$; Figure 2b). Cows fed the HND diet had increased haptoglobin on d 5, 7, 13, and $19(P<0.04)$, whereas cows fed the LND diet only demonstrated elevated haptoglobin on $\mathrm{d} 13$ and $19(P<$ 0.001; Figure 2d). By d 25, haptoglobin for both treatment groups was similar to that observed during the baseline period. Finally, there was a tendency for cows fed the LND diet to have slightly lower BHB than cows fed the HND diet, and both treatments exhibited differences from baseline (Table 7; Figure 2c). Compared with baseline, cows fed the HND diet tended to have decreased BHB on d $7(P<0.09)$ and had decreased BHB from d 13 to $25(P<0.02)$. Similarly, cows fed the
LND diet had decreased BHB from d 7 to 25 compared with the baseline period $(P<0.02)$.

At the end of the trial period (d 26), both treatments had similar BW (785.8 vs. 794.3 for LND and HND cows, respectively; $\mathrm{SE}=5.4 \mathrm{~kg} ; P=0.14)$ when accounting for BW at the time of enrollment. Although both treatment groups demonstrated increased BW from enrollment $(P<0.001)$, there was a tendency for cows fed the LND diet to gain less weight than cows fed the HND diet $(+43.1$ vs. $+53.1 \mathrm{~kg} ; \mathrm{SE}=5.1 ; P=$ 0.08). Similarly, no difference in BCS between treatments was detected at the end of the trial period (3.47 vs. $3.50 ; \mathrm{SE}=0.05 ; P=0.66$ ). However, by d 25 , both treatments exhibited an increase in BCS from the time of enrollment $(+0.16$ vs. $+0.15 ; \mathrm{SE}=0.05 ; P<0.006)$.

\section{DISCUSSION}

The objectives of this study were to investigate the effect of dietary transition at dry off on the behavior and physiology of dairy cows and the efficacy of using a greater magnitude change in ration nutrient density,

Table 6. Effect of dietary treatments on the reticulorumen $\mathrm{pH}$ of Holstein dairy cows

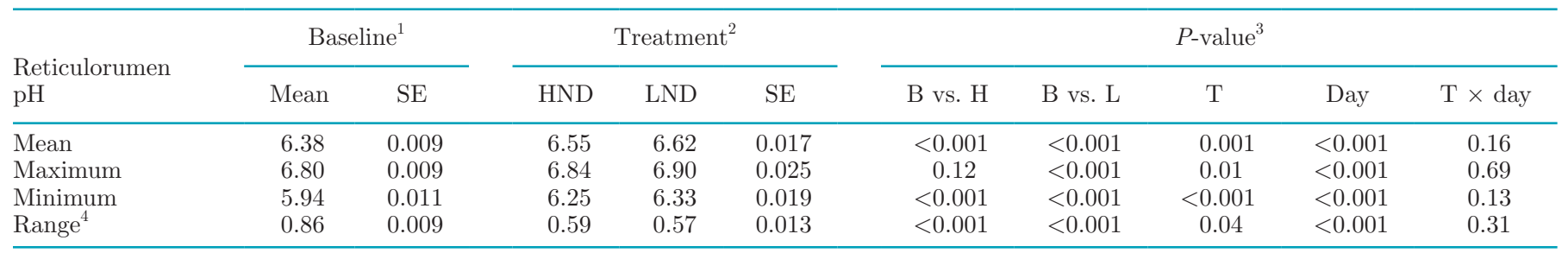

${ }^{1}$ Baseline $=16$-d period in late lactation immediately before the start of dry off.

${ }^{2} \mathrm{HND}=$ higher nutrient density diet $(1.55 \mathrm{Mcal} / \mathrm{kg}$ of $\mathrm{DM} ; \mathrm{n}=24) ; \mathrm{LND}=$ lower nutrient density diet $(1.48 \mathrm{Mcal} / \mathrm{kg}$ of $\mathrm{DM} ; \mathrm{n}=24)$. Treatment diets were fed over a 26 -d period, beginning at the start of a 5-d dry off and $21 \mathrm{~d}$ into the dry period.

${ }^{3} \mathrm{~B}$ vs. $\mathrm{H}=$ within-cow difference between baseline and HND treatment; $\mathrm{B}$ vs. $\mathrm{L}=$ within-cow difference between baseline and LND treatment; $\mathrm{T}=$ treatment effect.

${ }^{4}$ Range $=$ maximum - minimum. 
coupled with a reduction in milking frequency, to decrease milk production before dry off. Following $5 \mathrm{~d}$ of intermittent milkings, average milk yield was reduced by approximately $10 \mathrm{~kg} / \mathrm{d}$ from baseline for both magnitude changes in dietary nutrient density. The change in milking frequency from $2 \times / d$ to, at most, $1 \times / d$ was likely primarily responsible for the reduction in milk yield, as losses in milk yield when cows are switched to once-daily milking are well documented (see review by Davis et al., 1999). The decline in milk yield observed in the current study was similar to that reported by Zobel et al. (2013), wherein cows producing $24 \pm 5$ $\mathrm{kg} / \mathrm{d}$ at dry off experienced a decrease in milk yield of approximately $13 \mathrm{~kg}$ after a 5 -d period of skipped milkings. During those $5 \mathrm{~d}$, cows were fed oat straw ad libitum and approximately $10 \mathrm{~kg}$ of tall fescue hay/d, a lower plane of nutrition than the present study, which may have facilitated the greater decrease in milk yield.

Restriction of feed has been demonstrated to reduce milk yield in cows in peak lactation (Agenäs et al., 2003) as well as late lactation before dry off (Tucker et al., 2009). Although both treatment diets in the current study were fed ad libitum rather than restrictively and provided a higher level of nutrition during dry off compared with similar studies, treatment likely contributed to the decrease in milk production, as cows fed the LND diet experienced a greater reduction in milk yield than the HND cows during the dry-off period. This may be attributed to both the lower nutrient density and the detected difference in DMI, wherein LND cows had consistently lower DMI compared with HND cows.

Additionally, the effects of intermittent milkings observed in the current study at dry off on milk fat percentage, protein percentage, and SCC are consistent with changes observed in previous studies at dry off (Odensten et al., 2005, 2007) and when lactating cows are switched to $1 \times / \mathrm{d}$ milking (Davis et al., 1999). A concentration effect due to decreased milk production was likely responsible for these increases.

Once introduced to their respective treatment diets, all cows experienced a reduction in DMI, in particular the LND cows. This was not surprising because both treatment diets had higher NDF content compared with the lactating diet due to greater inclusion of forages. With higher NDF, the bulk density of the feed is often increased, which promotes physical fill of the rumen and limits voluntary DMI (Allen, 1996; Mertens, 1997). The treatment diets also had a greater proportion of long particles than the lactating cow diet, which may have further limited intake due to increased rumen retention time (Allen and Mertens, 1988). Thus, greater NDF content and proportion of long particles in the LND diet would have limited DMI to a greater extent than the HND diet. Despite lower DMI, cows in the 

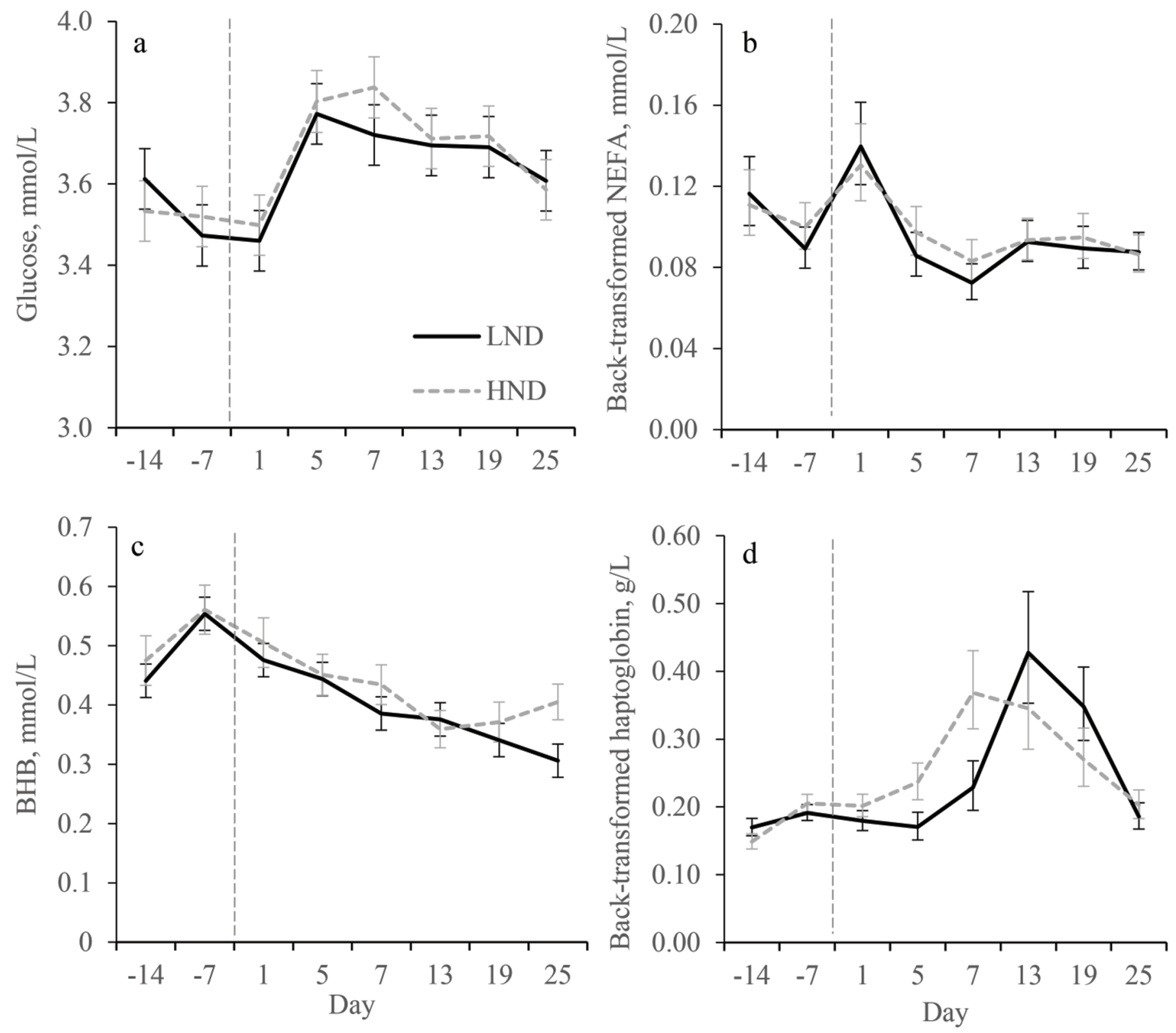

Figure 2. Average ( $\pm \mathrm{SE}$ ) for (a) serum glucose (mmol/L), (b) serum nonesterified fatty acid (NEFA; mmol/L), (c) whole-blood BHB $(\mathrm{mmol} / \mathrm{L})$, and $(\mathrm{d})$ serum haptoglobin $(\mathrm{g} / \mathrm{L})$ concentrations for cows fed 1 of 2 dietary treatments differing in ration nutrient density $(\mathrm{LND}=$ lower nutrient density; HND = higher nutrient density) undergoing a 5-d dry off beginning at d 1 (dotted vertical line).

current study spent more time feeding after receiving their respective treatment diet, with LND cows spending more time feeding than HND cows. These results are consistent with work by Jiang et al. (2017), who reported a linear increase in feeding time with greater inclusion of roughage in the diets of mid-lactation cows. Other researchers have also observed increased feeding time when cows were switched from a lactating TMR to lower quality feeds before dry off (Valizaheh et al., 2008; Zobel et al., 2013). In the present study, lower DMI but greater feeding time corresponded with slower average feeding rates following dietary transition, especially for cows fed the LND diet. Further to the effect of higher roughage inclusion promoting longer feeding times, forage type in the diet has been shown to affect feeding rate, with straw and hay having been shown to encourage slower rates of intake compared with silage (Beauchemin et al., 2008). These changes in feeding behavior on a daily basis were also reflected in meal patterning. Although cows had fewer meals per day following treatment diet implementation, total daily meal time increased and individual meals were of longer du- 
ration, with more nonfeeding time within meals. These changes can be attributed to slower feeding rates and greater time spent chewing (Jiang et al., 2017). There was also more time between meals for both treatments, and meals were smaller on a DM basis for LND cows, again likely a result of correspondingly increased gut fill from the greater bulk of both treatment diets, but especially the LND diet.

Unsurprisingly, cows in the current study sorted against the longest particles (which would be primarily straw) and in favor of the short and fine particles (which would be primarily corn from silage and supplement) within their respective diets. These results are in agreement with previous studies that have shown cows prefer the smaller, more palatable concentrate components of a TMR to the larger forage components (Leonardi and Armentano, 2003; Greter and DeVries, 2010). Furthermore, cows fed the LND diet sorted in favor of the short and fine particles to a greater extent than cows fed the HND diet. This contradicts work by DeVries et al. (2007) wherein lactating cows fed a lower forage diet (50.7\% forage) sorted more than cows fed a higher forage diet ( $62.3 \%$ forage), especially in sorting against long particles. The treatment diets used in the current study were approximately $80 \%$ forage DM, which may have contributed to the observed difference. Further, the higher forage ration used by DeVries et al. (2007) contained almost $5 \%$ more long particles on a DM basis compared with the LND diet used in the current study. This fact, coupled with the higher moisture content of the higher forage diet (41.4\% DM) compared with the lower forage diet (47.6\% DM; DeVries et al., 2007), may have resulted in a ration that was more difficult to sort (Leonardi et al., 2005). This would be consistent with the diets used in the current study, with the LND diet being of lower moisture content $(53.1 \% \mathrm{DM})$ than the HND diet $(50.9 \% \mathrm{DM})$.

The change from the lactating diet to the higher forage diets in the present study resulted in a greater extent of sorting for the short particles in both treatments and a greater extent of sorting for the fine particles for LND cows. These results indicate that the higher forage content of the LND diet facilitated sorting of the smaller, nutrient dense particles or that cows were motivated to sort more to compensate for the lower nutrient density of the diet. Greter and DeVries (2010) made associations between sorting and feeding rate in lactating dairy cows. In that study, a greater extent of sorting against long particles was associated with a slower feeding rate. It is possible in the present study that the increased sorting activity of LND cows could have contributed to the observed lower feeding rate if more time was being invested into manipulating the diet. Regardless of the reason, the sorting behavior observed in this study indicates that, on average, cows on both treatments were consuming a diet of higher nutrient density than intended, which could potentially put cows at greater risk of health disorders, such as ketosis, after calving (Mann et al., 2015). Accounting for the average sorting values observed in each treatment, HND cows consumed, on average, $1.56 \mathrm{Mcal} / \mathrm{kg}$ (compared with $1.55 \mathrm{Mcal} / \mathrm{kg}$ offered) and LND cows consumed $1.52 \mathrm{Mcal} / \mathrm{kg}$ (compared with $1.48 \mathrm{Mcal} /$ $\mathrm{kg}$ offered). Even before considering the effects of feed sorting on nutrient intake, both treatment diets were of relatively high nutrient densities for far-off dry cow diets (Dann et al., 2006). Consequently, cows gained both BW and BCS over the course of the 42-d study period, where ideally BCS would be maintained. At the observed rate of gain in BCS, cows would be at risk of exceeding the upper limit of the commonly recommended BCS range for calving (3.25-3.75).

Despite the preferential sorting for short and fine particles in the current study, reticulorumen $\mathrm{pH}$ was still increased compared with baseline and was consistently higher in LND cows than in HND cows, even though LND cows sorted for these particles to a greater extent. Sorting for the smaller components of the diet has been associated with increased production of VFA and decreased pH (Cook et al., 2004; DeVries et al., 2008). However, this effect may have been counteracted by the LND diet having greater NDF content in each of the particle size fractions compared with the HND diet, including the small and fine fractions, thereby stimulating more chewing activity and buffering of the rumen (Jiang et al., 2017).

Rumination time increased in both treatments following the dietary transition, which was to be expected due to the higher forage content of the treatment diets relative to the lactating diet. Increased forage inclusion increases physically effective fiber, which works to stimulate rumination (Yang and Beauchemin, 2009). That said, rumination time was similar between treatments, except for select days where HND cows ruminated more, despite the LND diet having a higher fiber content. This was likely because the LND diet also limited voluntary DMI and thus consumption of physically effective fiber. When rumination was expressed as rum/DMI, however, the LND diet stimulated more rumination activity on the majority of days. Similarly, Jiang et al. (2017) also reported that increasing dietary roughage did not affect overall rumination time but did increase rum/DMI.

Lying behavior has often been used as an indicator of cow comfort, whether that be for comparing different housing systems (Fregonesi and Leaver, 2001), assessing the effect of illness (Medrano-Galarza et al., 2012), detecting illness (King et al., 2017), or, most relevantly, 
assessing the effect of different dry-off strategies (e.g., Leitner et al., 2007; Tucker et al., 2009; Zobel et al., 2013). In relation to skipped milkings or dry off, decreased lying behavior is often associated with the discomfort of elevated udder pressure from milk stasis (Österman and Redbo, 2001; O'Driscoll et al., 2011). In the current study, however, daily lying time was similar to baseline for LND cows and was greater for HND cows relative to baseline. Because cows no longer needed to stand for milking $2 \times / \mathrm{d}$ following dry off, it is expected that cows in both treatment groups would have more time to allocate to lying and feeding behavior. Cows in the HND group also spent less time feeding per day than LND cows, which could have allowed them to allocate more time to lying down compared with LND cows. Cows fed the HND diet had more lying bouts per day than cows fed the LND diet, and this may again be related to feeding behavior in that HND cows also had more meals per day on certain days, potentially interrupting lying bouts. In contrast, Zobel et al. (2013) observed reduced lying time and lying bouts following dry off. However, in that study average lying time and the number of bouts of both abruptly and gradually dried off cows were of similar values to those observed after dry off in the current study. Those authors also suggested that the changes in lying behavior following dry off could at least partly be explained by increased feeding time. Thus, in the current study, the observed differences in lying behavior appear to be the result of management changes rather than discomfort due to dry off and cessation of milking. This is further supported by the lack of difference between treatments in lying time as a percentage of free time.

Following the final milking during the gradual dry off, serum glucose concentration was elevated from baseline in both treatment groups. These results are consistent with Odensten et al. (2005), wherein increased glucose concentration was observed during a 5-d dry off in cows fed ad libitum straw and $4 \mathrm{~kg}$ of DM silage/d. Cows fed only dry hay in the $5 \mathrm{~d}$ before dry off also demonstrated increased glucose following cessation of milking (Ollier et al., 2014). The detected increases in glucose may be the result of decreased mammary uptake of glucose for lactose synthesis (Shennan and Peaker, 2000). Although not measured in the present study, Odensten et al. (2005) observed decreased lactose concentration in milk during dry off. Those researchers saw glucose return to pre-dry-off levels by d 4 of the dry-off period; however, in the current study, glucose did not return to baseline levels until more than $19 \mathrm{~d}$ after the start of dry off. This difference may be associated with the relatively high plane of nutrition in the current study compared with that of Odensten et al. (2005). In the present study, NEFA increased briefly at the start of dry off on d 1. The reason for this increase was likely the magnitude change in ration nutrient density, wherein cows were at first reluctant to consume their respective treatment diets due to its lower palatability compared with the lactating diet. Because cows were still producing $26 \mathrm{~kg} / \mathrm{d}$, on average, at the time dry off began, the nutrient demands for milk and a reduction in DMI likely resulted in mobilization of body fat. That said, NEFA returned to levels similar to or lower than baseline by the day of dry off. In comparison, Odensten et al. (2005) observed a marked increase in NEFA in cows fed straw and silage at dry off and especially in cows fed only straw, indicating a reduction in energy balance. From the start of dry off, BHB in the present study gradually decreased into the dry period. Odensten et al. (2005) also observed decreased BHB following the start of dry off despite NEFA increasing, and other researchers have indicated that BHB may not be appropriate as an indicator of energy balance except during early lactation (Chilliard et al., 1995; Drackley, 1999).

Finally, haptoglobin is an acute phase protein that may be used to indicate disease in cattle (Alsemgeest et al., 1994) and is produced in response to acute stressors such as inflammation, infection, or trauma. Following dry off on d 5, HND cows immediately exhibited increased haptoglobin until at least d 19, whereas LND cows exhibited increased haptoglobin only from d 13 to 19. In a study wherein haptoglobin was measured at dry off, close up, and following calving, Abuelo et al. (2016) reported haptoglobin concentrations at dry off similar to those observed in the current study during the baseline period and until d 5 of dry off. Unfortunately, the dry-off protocol was not included in that study because its objective was directed toward the development of claw lesions during lactation rather than investigating dry-off practices. To our knowledge, the study of Odensten et al. (2007) is the only other than the present study to measure acute phase protein at multiple time points surrounding dry off; however, almost all haptoglobin concentrations in that study were below the range of detection. Those researchers did, however, test for the acute phase protein serum amyloid A as well and observed increased serum amyloid A during dry off in cows fed straw as well as straw and silage. The serum haptoglobin concentrations observed in the current study, as well as the serum amyloid A concentrations observed by Odensten et al. (2007), may be comparable with those in cows with mild or moderate mastitis, respectively (Eckersall et al., 2001), and were likely elevated as a reaction to involution of the udder eliciting an inflammatory response. 


\section{CONCLUSIONS}

In the current study, dietary transition at dry off resulted in both behavioral and physiological changes, especially when the magnitude change in dietary nutrient density was greater. In this study, cows fed the LND diet had lower DMI, spent more time feeding, and fed at a slower rate than cows fed the HND diet. Feeding strategy also affected meal patterning and sorting behavior, with cows fed the LND diet sorting for short and fine particles to a greater extent than cows fed the HND diet. Finally, feeding diets of lower nutrient density before dry off and milking intermittently facilitated a reduction in milk production before cessation of milking while not substantially altering cow physiology.

\section{ACKNOWLEDGMENTS}

We thank the staff of the University of Guelph Livestock Research and Innovation Centre - Dairy Facility (Elora, ON, Canada), especially Laura Wright for all her assistance facilitating this research project. Special thanks to Michelle Thompson, Kaitlin Sparkman, Isabela Salmazo, Sarah McPherson, and Felipe Pádua of the University of Guelph (Guelph, ON, Canada) for their assistance with data collection. This project was financially supported by a Natural Sciences and Engineering Research Council of Canada (Ottawa, ON, Canada) Discovery Grant. Equipment for this project was supported through contributions from the Canadian Foundation for Innovation (Ottawa, ON, Canada) and the Ontario Research Fund (Toronto, ON, Canada).

\section{REFERENCES}

Abuelo, A., J. C. Gandy, L. Neuder, J. Brester, and L. M. Sordillo. 2016. Markers of oxidant status and inflammation relative to the development of claw lesions associated with lameness in early lactation dairy cows. J. Dairy Sci. 99:1-9. https://doi.org/10.3168/ jds.2015-10707.

Agenäs, S., K. Dahlborn, and K. Holtenius. 2003. Changes in metabolism and milk production during and after feed deprivation in primiparous cows selected for different milk fat content. Livest. Prod. Sci. 83:153-164. https://doi.org/10.1016/S0301-6226(03)00096-4.

Allen, M. S. 1996. Physical constraints on voluntary intake of forages by ruminants. J. Anim. Sci. 74:3063-3075.

Allen, M. S., and D. R. Mertens. 1988. Evaluating constraints of fiber digestion by rumen microbes. J. Nutr. 118:261-270.

Alsemgeest, S. P., H. C. Kalsbeek, T. Wensing, J. P. Koeman, A. M. van Ederen, and E. Gruys. 1994. Concentrations of serum amyloid-A (SAA) and haptoglobin (HP) as parameters of inflammatory diseases in cattle. Vet. Q. 16:21-23. https://doi.org/10.1080/ 01652176.1994 .9694410$.

AOAC International. 2000. Official Methods of Analysis. Vol. I. 17th ed. AOAC International, Arlington, VA.

Bachman, K. C., and M. L. Schairer. 2003. Invited review: Bovine studies on optimal lengths of dry periods. J. Dairy Sci. 86:30273037. https://doi.org/10.3168/jds.S0022-0302(03)73902-2.
Beauchemin, K. A., L. Eriksen, P. Nørgaard, and L. M. Rode. 2008. Salivary secretion during meals in lactating dairy cattle. J. Dairy Sci. 91:2077-2081. https://doi.org/10.3168/jds.2007-0726.

Bertulat, S., C. Fischer-Tenhagen, V. Suthar, E. Möstl, N. Isaka, and W. Heuwieser. 2013. Measurement of fecal glucocorticoid metabolites and evaluation of udder characteristics to estimate stress after sudden dry-off in dairy cows with different milk yields. J. Dairy Sci. 96:3774-3787. https://doi.org/10.3168/jds.2012-6425.

Blowey, R., and P. Edmondson. 2010. Mastic Control in Dairy Herds. 2nd ed. CAB International, Oxfordshire, UK.

Bushe, T., and S. P. Oliver. 1987. Natural protective factors in bovine mammary secretions following different methods of milk cessation. J. Dairy Sci. 70:696-704. https://doi.org/10.3168/jds.S0022 -0302(87)80060-7.

Canadian Council on Animal Care. 2009. Guidelines on: The Care and Use of Farm Animals in Research, Teaching and Testing. Canadian Council on Animal Care, Ottawa, ON, Canada.

Chapinal, N., D. M. Veira, D. M. Weary, and M. A. G. von Keyserlingk. 2007. Technical note: Validation of a system for monitoring individual feeding and drinking behaviour and intake in group housed dairy cows. J. Dairy Sci. 90:5732-5736. https://doi.org/10 .3168/jds.2007-0331.

Chilliard, Y., M. Doreau, F. Bocquier, and G. E. Lobley. 1995. Digestive and metabolic adaptations of ruminants to variations in food supply. Pages 329-360 in Recent Developments in the Nutrition of Herbivores. M. Journet, E. Grenet, M. H. Farce, M. Thériez, and C. Demarquilly, ed. INRA, Paris, France.

Cook, N. B., K. V. Nordlund, and G. R. Oetzel. 2004. Environmental influences on claw horn lesions associated with laminitis and subacute ruminal acidosis in dairy cows. J. Dairy Sci. 87:E36-E46. https://doi.org/10.3168/jds.S0022-0302(04)70059-4.

Dann, H. M., N. B. Litherland, J. P. Underwood, M. Bionaz, A. D'Angelo, J. W. McFadden, and J. K. Drackley. 2006. Diets during far-off and close-up dry periods affect periparturient metabolism and lactation in multiparous cows. J. Dairy Sci. 89:3563-3577. https://doi.org/10.3168/jds.S0022-0302(06)72396-7.

Davis, S. R., V. C. Farr, and K. Stelwagen. 1999. Regulation of yield loss and milk composition during once-daily milking: A review. Livest. Prod. Sci. 59:77-94. https://doi.org/10.1016/S0301 $-6226(98) 00204-8$.

DeVries, T. J., K. A. Beauchemin, and M. A. G. von Keyserlingk. 2007. Dietary forage concentration affects the feed sorting behavior of lactating dairy cows. J. Dairy Sci. 90:5572-5579. https://doi .org/10.3168/jds.2007-0370.

DeVries, T. J., F. Dohme, and K. A. Beauchemin. 2008. Repeated ruminal acidosis challenges in lactating dairy cows at high and low risk for developing acidosis: Feed sorting. J. Dairy Sci. 91:39583967. https://doi.org/10.3168/jds.2008-1347.

DeVries, T. J., M. A. G. von Keyserlingk, D. M. Weary, and K. A. Beauchemin. 2003. Technical note: Validation of a system for monitoring feeding behavior of dairy cows. J. Dairy Sci. 86:3571-3574. https://doi.org/10.3168/jds.S0022-0302(03)73962-9.

Dingwell, R. T., D. F. Kelton, K. E. Leslie, and V. L. Edge. 2001. Deciding to dry-off: Does level of production matter? Pages 69-79 in Proc. Natl. Mastitis Counc. Ann. Mtg. National Mastitis Council, Madison, WI.

Dingwell, R. T., K. E. Leslie, Y. H. Schukken, J. M. Sargeant, L. L. Timms, T. F. Duffield, G. P. Keefe, D. F. Kelton, K. D. Lissemore, and J. Conklin. 2004. Association of cow and quarter-level factors at drying-off with new intramammary infections during the dry period. Prev. Vet. Med. 63:75-89. https://doi.org/10.1016/j .prevetmed.2004.01.012.

Drackley, J. K. 1999. Biology of dairy cows during the transition period: The final frontier. J. Dairy Sci. 82:2259-2273.

Eckersall, P. D., F. J. Young, C. McComb, C. J. Hogarth, S. Safi, A. Weber, T. Mcdonald, A. M. Nolan, and J. L. Fitzpatrick. 2001. Acute phase proteins in serum and milk from dairy cows with clinical mastitis. Vet. Rec. 148:35-41.

Falk, M., A. Münger, and F. Dohme-Meier. 2016. Technical note: A comparison of reticular and ruminal $\mathrm{pH}$ monitored continuously 
with 2 measurement systems at different weeks of early lactation. J. Dairy Sci. 99:1951-1955. https://doi.org/10.3168/jds.2015-9725.

Fregonesi, J. A., and J. D. Leaver. 2001. Behaviour, performance and health indicators of welfare for dairy cows housed in strawyard or cubicle systems. Livest. Prod. Sci. 68:205-216. https://doi.org/10 .1016/S0301-6226(00)00234-7.

Greter, A. M., and T. J. DeVries. 2010. Effect of feeding amount on the feeding and sorting behaviour of lactating dairy cattle. Can. J. Anim. Sci. 91:47-54. https://doi.org/10.4141/CJAS10067.

Jiang, F. G., X. Y. Lin, Z. G. Yan, Z. Y. Hu, G. M. Liu, Y. D. Sun, X. W. Liu, and Z. H. Wang. 2017. Effect of dietary roughage level on chewing activity, ruminal $\mathrm{pH}$, and saliva secretion in lactating Holstein cows. J. Dairy Sci. 100:2660-2671. https://doi.org/10 $.3168 /$ jds.2016-11559.

Kanz, P., M. Drillich, D. Klein-Jöbstl, B. Mair, S. Borchardt, L. Meyer, I. Schwendenwein, and M. Iwersen. 2015. Suitability of capillary blood obtained by a minimally invasive lancet technique to detect subclinical ketosis in dairy cows by using 3 different electronic hand-held devices. J. Dairy Sci. 98:6108-6118. https://doi .org/10.3168/jds.2014-8957.

King, M. T. M., K. M. Dancy, S. J. LeBlanc, E. A. Pajor, and T. J. DeVries. 2017. Deviations in behavior and productivity data before diagnosis of health disorders in cows milked with an automated system. J. Dairy Sci. 100:8358-8371. https://doi.org/10 $.3168 /$ jds.2017-12723.

Ledgerwood, D. N., C. Winckler, and C. B. Tucker. 2010. Evaluation of data loggers, sampling intervals, and editing techniques for measuring the lying behavior of dairy cattle. J. Dairy Sci. 93:5129 5139. https://doi.org/10.3168/jds.2009-2945.

Leitner, G., S. Jacoby, E. Maltz, and N. Silanikove. 2007. Casein hydrolyzate intramammary treatment improves the comfort behavior of cows induced into dry-off. Livest. Sci. 110:292-297. https://doi .org/10.1016/j.livsci.2007.02.016

Leonardi, C., and L. E. Armentano. 2003. Effect of quantity, quality, and length of alfalfa hay on selective consumption by dairy cows. J. Dairy Sci. 86:557-564. https://doi.org/10.3168/jds.S0022 -0302(03)73634-0.

Leonardi, C., F. Giannico, and L. E. Armentano. 2005. Effect of water addition on selective consumption (sorting) of dry diets by dairy cattle. J. Dairy Sci. 88:1043-1049. https://doi.org/10.3168/jds .S0022-0302(05)72772-7.

MacDonald, P. D. M., and P. E. J. Green. 1988. User's Guide to Program MIX: An Interactive Program for Fitting Mixtures of Distributions. Release 2.3. Ichthus Data Systems, Hamilton, ON, Canada.

Mann, S., F. A. Leal Yepes, T. R. Overton, J. J. Wakshlag, A. L. Lock, C. M. Ryan, and D. V. Nydam. 2015. Dry period plane of energy: Effects on feed intake, energy balance, milk production, and composition in transition dairy cows. J. Dairy Sci. 98:3366-3382. https://doi.org/10.3168/jds.2014-9024.

Maulfair, D. D., M. Fustini, and A. J. Heinrichs. 2011. Effect of varying total mixed ration particle size on rumen digesta and feca particle size and digestibility in lactating dairy cows. J. Dairy Sci. 94:3527-3536. https://doi.org/10.3168/jds.2010-3718.

Maulfair, D. D., and A. J. Heinrichs. 2013. Effects of varying forage particle size and fermentable carbohydrates on feed sorting, ruminal fermentation, and milk and component yields of dairy cows. J. Dairy Sci. 96:3085-3097. https://doi.org/10.3168/jds.2012-6048.

Medrano-Galarza, C., J. Gibbons, S. Wagner, A. M. de Passillé, and J. Rushen. 2012. Behavioral changes in dairy cows with mastitis. J. Dairy Sci. 95:6994-7002. https://doi.org/10.3168/jds.2011-5247.

Mertens, D. R. 1997. Creating a system for meeting the fiber requirements of dairy cows. J. Dairy Sci. 80:1463-1481. https://doi.org/ 10.3168/jds.S0022-0302(97)76075-2.

NRC. 2001. Nutrient Requirements of Dairy Cattle. 7th rev. ed. Natl. Acad. Press, Washington, DC.
O'Driscoll, K., D. Gleeson, B. O'Brien, and L. Boyle. 2011. Does omission of a regular milking event affect cow comfort? Livest. Sci. 138:132-143. https://doi.org/10.1016/j.livsci.2010.12.013.

Odensten, M. O., Y. Chilliard, and K. Holtenius. 2005. Effects of two different feeding strategies during dry-off on metabolism in highyielding dairy cows. J. Dairy Sci. 88:2072-2082. https://doi.org/10 .3168/jds.S0022-0302(05)72884-8.

Odensten, M. O., K. Holtenius, and K. Persson Waller. 2007. Effects of two different feeding strategies during dry-off on certain health aspects of dairy cows. J. Dairy Sci. 90:898-907. https://doi.org/10 .3168/jds.S0022-0302(07)71573-4.

Ollier, S., X. Zhao, and P. Lacasse. 2014. Effects of feed restriction and prolactin-release inhibition at drying off on metabolism and mammary gland involution in cows. J. Dairy Sci. 97:4942-4954. https: /doi.org/10.3168/jds.2014-7914.

Österman, S., and I. Redbo. 2001. Effects of milking frequency on lying down and getting up behaviour in dairy cows. Appl. Anim. Behav. Sci. 70:167-176.

Rajala-Schultz, P. J., J. S. Hogan, and K. L. Smith. 2005. Association between milk yield at dry-off and probability of intramammary infections at calving. J. Dairy Sci. 88:577-579. https://doi.org/10 .3168/jds.S0022-0302(05)72720-X.

SAS Institute Inc. 2013. SAS Version 9.4. SAS Institute Inc., Cary, NC.

Schirmann, K., M. A. von Keyserlingk, D. M. Weary, D. M. Veira, and W. Heuwieser. 2009. Technical note: Validation of a system for monitoring rumination in dairy cows. J. Dairy Sci. 92:6052-6055. https://doi.org/10.3168/jds.2009-2361.

Shennan, D. B., and M. Peaker. 2000. Transport of milk constituents by the mammary gland. Physiol. Rev. 80:925-951.

Skidmore, A., K. Peeters, C. Sniffen, and A. Brand. 1997. Monitoring dry period management. Pages 171-201 in Herd Health and Production Management in Dairy Practice. A. Brant, J. Noordhuizen, and Y. Schukken, ed. Wageningen Pers, Wageningen, the Netherlands.

Stefanon, B., M. Colitti, G. Gabai, C. H. Knight, and C. J. Wilde. 2002. Mammary apoptosis and lactation persistency in dairy animals. J. Dairy Res. 69:37-52

Ster, C., M. C. Loiselle, and P. Lacasse. 2012. Effect of postcalving serum nonesterified fatty acids concentration on the functionality of bovine immune cells. J. Dairy Sci. 95:708-717. https://doi.org/ 10.3168/jds.2011-4695.

Tucker, C. B., S. J. Lacy-Hulbert, and J. R. Webster. 2009. Effect of milking frequency and feeding level before and after dry off on dairy cattle behavior and udder characteristics. J. Dairy Sci. 92:3194-3203. https://doi.org/10.3168/jds.2008-1930.

Valizaheh, R., D. M. Veira, and M. A. G. von Keyserlingk. 2008. Behavioural responses by dairy cows provided two hays of contrasting quality at dry-off. Appl. Anim. Behav. Sci. 109:190-200. https:/ doi.org/10.1016/j.applanim.2007.03.001.

Van Soest, P. J., J. B. Robertson, and B. A. Lewis. 1991. Methods for dietary fiber, neutral detergent fiber and non-starch polysaccharide in relation to animal nutrition. J. Dairy Sci. 74:3583-3597. https://doi.org/10.3168/jds.S0022-0302(91)78551-2.

Wildman, E. E., G. M. Jones, P. E. Wagner, and R. L. Bowman. 1982. A dairy cow body condition scoring system and its relationship to selected production characteristics. J. Dairy Sci. 65:495-501. https://doi.org/10.3168/jds.S0022-0302(82)82223-6.

Yang, W. Z., and K. A. Beauchemin. 2009. Increasing physically effective fiber content of dairy cow diets through forage proportion versus forage chop length: Chewing and ruminal pH. J. Dairy Sci. 92:1603-1615. https://doi.org/10.3168/jds.2008-1379.

Zobel, G., K. Leslie, D. M. Weary, and M. A. G. von Keyserlingk. 2013 Gradual cessation of milking reduces milk leakage and motivation to be milked in dairy cows at dry-off. J. Dairy Sci. 96:5064-5071. https://doi.org/10.3168/jds.2012-6501. 